\title{
A Storytelling Map of the Upper Mara Valley
}

\author{
Gabriela ILIES1 and Marin ILIES²
}

Babes-Bolyai University, Faculty of Geography, Sighetu Marmatiei Extension

6 Avram lancu Street, 435500 Sighetu Marmatiei, Romania

19abriela.ilies@ubbcluj.ro, 2marin.ilies@ubbcluj.ro

Abstract. Storytelling maps have recently become increasingly popular, as they provide access to otherwise inaccessible places or services. A printed map is a tangible object which mediates the storytelling process. This particular map, featuring the adventures of Pintea Viteazul (Pintea the Brave), a Romanian folk-hero, is designed to enhance tourist experiences during outdoor activities in a mountain area with relatively accessible infrastructure and scenic features: the Mara Valley and Creasta Cocosului (Maramureș, Romania). The main research questions revolved around the experience design. The research was based on designing and testing a specific storytelling map for mountain tourism. The main stages of development were the experience design and the map itself. Focusing on a complex geographic location famous for its volcanic relief and folk tales, it tells the story of the mountain by tracing a parallel between geological features and a national legend.

Keywords: storytelling map, experiential, Maramureș

\section{Introduction}

Maps are often used as storytelling communication tools, for example tour guides (ESRI 2012). Successful stories incorporate maps to locate the action, drama and characters using a variety of media: print, film, or video games. The viewer is drawn in and immersed (Strain 2003). The map reader first becomes the viewer; then the viewer becomes a character in their own story. Various proprietary and open-source platforms capitalize on this by providing storytelling apps, templates and support. There are at least twelve kinds of storytelling maps. Not all of them are designed to document past experiences (ESRI 2010).

The particular map which is the subject of this paper was designed to enhance tourist experiences during outdoor activities in a mountain area with relatively accessible infrastructure and scenic features: the Mara Valley and Creasta Cocosului (Maramureş, Romania).

The region is Romania's first ecotourism destination, established in 2014 by the Ministry of Tourism,

16 covering seven important nature reserves and traditional villages. Its nomination triggered the development of basic ecotourism services there, mostly managed by the association leading the project (Ecologic Maramureş) and the World Wildlife Fund (URL1). Complex tourist activities are provided by travel agents from Maramureș, Transylvania, and Bucharest. They capitalise on the Maramureş tourism brand, using basic cartographic products for hiking, cycling, and exploring the villages. According to data provided by the tourist information centre in Sighetu Marmatiei (URL2), Romanian tourists rarely use maps for route-finding, due to their low skills in map reading. In contrast, foreign tourists (Polish, German, and French) request good maps when they arrive, even if they have come well prepared.

The available cartographic products for the study area range from printed general 1:100 000 maps and their on-line counterparts, through smaller-scale printed mountain maps for Creasta Cocosului and the Ignis Mountains area, to climbing sketches and trailhead

KiG No. 30, Vol. 17, 2018, https://doi.org/10.32909/kg.17.30.2 —- 


\title{
Karta gornje doline Mara - pripovjedna karta
}

\author{
Gabriela ILIES1 i Marin ILIES2 \\ Sveučilište Babes-Bolyai, Geografski fakultet, Podružnica Sighetu Marmatiei \\ 6 Avram lancu Street, 435500 Sighetu Marmatiei, Rumunjska \\ 1gabriela.ilies@ubbcluj.ro, 2marin.ilies@ubbcluj.ro
}

Sažetak. Pripovjedne su karte sve popularnije među nastavnicima i trgovcima jer nude poticaje na inače neopipljivim mjestima ili uslugama. Zbog toga opipljivi objekt - tiskana karta posreduje u procesu pripovijedanja. Ova je karta osmišljena kako bi se povećala iskustva turista tijekom aktivnosti na otvorenom u planinskom području s relativno pristupačnim infrastrukturama i slikovitim fizičkim značajkama: dolina Mara i Creasta Cocosului (Maramureș, Rumunjska). Glavna pitanja istraživanja usmjerena su na dizajn iskustva. Istraživanje se temelji na izradi i testiranju specifične pripovjedne karte u planinskom turizmu. Stoga su glavne faze razvoja oblikovanje iskustva i karta. Usredotočujući se na složene geografske lokalitete s vulkanskim reljefom i bogatim herojskim pripovijestima, karta priča 0 planini pronalazeći paralelu između geoloških obilježja i nacionalne legende.

Ključne riječi: pripovjedna karta, iskustvo, Maramureș

\section{Uvod}

Općenito, karte kao komunikacijski alati imaju atribut pripovjedača sa ili bez ljudske intervencije, kao npr. turistički vodiči (ESRI 2012). Ipak, uspješne priče uključuju karte u proces prostornog smještaja akcija, drame i likova, a koji se prenose na različite tiskane medije, filmove i videoigre. Karte gledatelja privlače i dalje potiču njegovo daljnje uranjanje (Strain 2003). Čitatelj karte postaje gledatelj, gledatelj se pretvara u lika vlastite priče. Na tome zarađuju mnoge vlasničke i open-source platforme pružajući aplikacije, predloške i podršku za pripovijedanje. Pripovjedne karte nisu dizajnirane samo za bilježenje prošlih iskustava i ima ih najmanje dvanaest vrsta (ESRI 2010).

Ova je karta osmišljena kako bi se povećala iskustva turista tijekom aktivnosti na otvorenom u planinskom području s relativno pristupačnim infrastrukturama i slikovitim fizičkim značajkama: dolina Mara i Creasta Cocosului (Maramureș, Rumunjska).

To je područje prva rumunjska destinacija za ekoturizam koju je 2014. godine osnovalo Ministarstvo turizma, a koje sadrži sedam važnih mjesta za očuvanje prirode i tradicionalnih sela. Nominacija je potaknula razvoj osnovnih usluga za ekoturizam a njima je uglavnom upravljala udruga koja je vodila projekt (Ecologic Maramureş) i WWF (URL1). Složenije turističke aktivnosti provode putničke agencije u Maramureşu, Transilvaniji i Bukureštu. Oni kapitaliziraju turistički brend Maramureş koristeći osnovne kartografske proizvode za planinarenje, biciklizam, šetnju po selima itd. Štoviše, rumunjski turistički profil regije, prema podatcima turističkog informativnog centra u Sighetu Marmatiei (URL2), otkriva da turisti (zbog kronične nepismenosti u čitanju karata) rijetko koriste karte za pronalaženje ruta. Nasuprot tome, ista studija pokazuje da strani turisti (poljski, njemački i francuski), čak i kada su pri dolasku dobro pripremljeni, traže dobre karte.

Dostupnost kartografskih proizvoda za područje proučavanja kreće se od tiskanih općih karata u mjerilu $1: 100000$ i njihovih online pratioca, preko tiskanih planinskih karata sitnijeg mjerila za područja Creasta Cocosului ili planine Ignis, do skica za penjanje i postavljanja znakova za početak staze. Turoperatori rijetko koriste te 
signposting. Tour operators rarely use these, because availability is very limited. There are no available business portfolio maps or commercially-produced maps. This is why we wanted to test the storytelling map as a teaser for marketing tourism and as a teaching tool.

The general aim of this paper was to examine the potential of storytelling maps to enhance tourist experiences during outdoor activities in mountain areas. The main research questions revolved around the experience design. (1) What was the role of the story told by the map in managing tourist experiences? (2) What were the main features of the tourist map that triggered the co-creation of experiences? (3) If used as teaser advertising, might such a map spoil multisensory experience?

\section{Material and methods}

The research was based on designing and testing a specific storytelling map in experiential mountain tourism. The main stages of development were the experience design and the map.

Firstly, we conceived a special mountain map as a teaser or marketing tool for educational mountaineering services (guided tours). Focusing on a complex geographic location famous for its volcanic relief and folk tales, the map told the story of the mountain by tracing a parallel between the geological features and a national legend (Pintea the Brave, the Romanian 'Robin Hood'). Finally, a graphic design process was applied incorporating multimedia files. The map scale was 1:10 000, printed on a $50 \times 70 \mathrm{~cm}$ sheet. There was also an online version. The area covered part of the upper Mara Valley, $600 \mathrm{~m}$ to $1444 \mathrm{~m}$ in elevation.

Secondly, our research into tourist experiences involved designing testing tools to understand the role of a storytelling map in a multisensory experience and the needs of users, and to avoid a staged experience. Testing was preceded by a thorough assessment of the measurement approach, mainly in the area of visitors' preferences. Tools were targeted at potential visitors and professionals working in the area. Pre-testing focused on the most interesting elements of the story to be integrated in the map, particularly outlining the needs of young users regarding mapping products. The second tool was designed to assess different types of use for the map during guided tours.

Pre-testing consisted of a simple, direct survey to evaluate criteria such as general aspect, layers, multimedia usage and scenario on a relative ranking scale, targeted at high school or university students, selected from the region by age, gender, level of education and background. The survey was conducted as part of a larger endeavour at a local high school in Sighetu Marmatiei (Maramureş, Romania). It involved 533 students during the last semester of 2016/2017 (Table 1).

Table 1 Demographic overview of respondents participating in the pre-testing process

\begin{tabular}{lcc}
\hline Variable & Frequency & Percentage (\%) \\
\hline Age & 482 & 90.4 \\
$15-19$ & 51 & 9.6 \\
$20-25$ & & \\
Gender & 310 & 58 \\
Male & 232 & 42 \\
Female & & \\
Current educational level & & \\
Technical qualification & 90 & 16.8 \\
High school & 392 & 73.5 \\
Undergraduate studies & 36 & 6.7 \\
Graduate studies & 15 & 2.8 \\
Background & & \\
Urban & 170 & 32 \\
Rural & 363 & 68 \\
\hline
\end{tabular}

We asked the students about the general aspects of the map they preferred for four types of tourist experience scenarios. These were derived from the main functional spatial abilities described by Todd Bacastow (2014): context, spatial patterns recognition, recall of previously observed objects, and integration of observation series, object rotation and scene visualization (Table 2).

At the same time, we conducted an assessment of different types of map used during guided tours. We carried out interviews with six local guides and tourist information office employees in the area (Table 3).

Experience tourism scenarios were created to determine visitor preferences for active or passive features in the protected area of the Gutai Mountains and the upper Mara Valley. The working hypothesis was that tourists would opt for a less active tour (Moyle et al. 2014), unless teaser advertisement and well-coordinated communication were established. If used as a teaser without giving away too much information, a storytelling map would probably have an inconclusive effect on a multisensory experience. Each scenario was presented by a certain map of the area. However, the terms of reference for scenario building were a classical hiking tour

KiG No. 30, Vol. 17, 2018, https://doi.org/10.32909/kg.17.30.2 - - 
materijale jer imaju vrlo ograničenu dostupnost. Karte poslovnih tvrtki i komercijalno izrađene karte nisu dostupne. Zato smo pripovjednu kartu iskušali kao provokaciju za marketing turističkog proizvoda, ali i kao alat za učenje.

Opći je cilj ovog rada ispitati značajke pripovjednih karata kako bi se povećala iskustva turista tijekom aktivnosti na planinskim područjima. Glavna pitanja istraživanja usmjerena su na dizajn iskustva. (1) Koja je uloga priče iz karte $\mathrm{u}$ upravljanju iskustvima turista? (2) Koja su glavna obilježja turističke karte koja bi mogla potaknuti stvaranje iskustava? (3) Ako se upotrebljava kao provokacija oglašavanja, može li uništiti višesenzorsko iskustvo?

\section{Materijali i metode}

Istraživanje se temelji na dizajniranju i testiranju specifične pripovjedne karte $u$ iskustvenom planinskom turizmu, a glavne su faze razvoja oblikovanje iskustva i karta.

Prvo, karta je posebna planinska karta, zamišljena kao provokator, kao marketinški alat za planinarske usluge (vođene ture) i podučavanje. Usredotočujući se na složene geografske lokalitete s vulkanskim reljefom i bogatim herojskim pripovijestima, karta priča o planini pronalazeći paralelu između geoloških obilježja i nacionalne legende. Konačno, primijenjeno je grafičko oblikovanje i uključene su multimedijske datoteke. Karta je otisnuta na listu veličine $50 \times 70 \mathrm{~cm}$, a mjerilo karte je 1 : 10 000. Postoji i online verzija. Područje pokriva dio gornje doline Mara, na nadmorskoj visini 600-1444 m.

Drugo, istraživanje o iskustvu u turizmu uključuje dizajniranje alata za testiranje kako bi se razumjelo što je uloga pripovjedne karte $u$ višesenzornom iskustvu, što su potrebe potrošača i kako se može izbjeći određeno postavljeno iskustvo. Međutim, testiranju je prethodila temeljita procjena pristupa mjerenju, uglavnom $u$ području preferencija posjetitelja. Zato se alati usmjeravaju na potencijalne posjetitelje i stručnjake koji rade na tom području. Prethodna ispitivanja usredotočuju se na najzanimljivije elemente priče koji će se integrirati u kartu, a koji ukazuju na potrebe mladih klijenata u vezi s kartografskim proizvodima. Drugi je alat osmišljen kako bi se, za vrijeme vođenja ture, procijenile različite vrste upotrebe karte.

Predtestiranje se sastojalo od jednostavnog izravnog istraživanja organiziranog za procjenu različitih kriterija kao što su opći aspekt, slojevi, multimedijska upotreba i scenarij na relativnoj ljestvici raspona, namijenjen mladim osobama upisanima $u$ neki oblik obrazovanja (srednju školu ili sveučilište), uzorkovano po dobi, spolu, razini obrazovanja i podrijetlu. Istraživanje je provedeno kao dio većeg pedagoškog pothvata na lokalnoj srednjoj školi u Sighetu Marmatiei (Maramureş, Rumunjska). Što se tiče demografskog pregleda ispitanika, anketa je primijenjena na 533 učenika tijekom posljednjeg semestra 2016-2017 (tablica 1).

Tablica 1. Demografski pregled ispitanika koji sudjeluju u predtestiranju

\begin{tabular}{lcc}
\hline Varijable & Frekvencija & Postotak (\%) \\
\hline Starost & & \\
15-19 godina & 482 & 90,4 \\
20-25 godina & 51 & 9,6 \\
Spol & & \\
muški & 310 & 58 \\
ženski & 232 & 42
\end{tabular}

\section{Trenutni stupanj obrazovanja}

tehnička kvalifikacija $\quad 90$

srednja škola $\quad 392 \quad 73,5$

preddiplomski studij $\quad 36 \quad 6,7$

$\begin{array}{lll}\text { diplomski studij } \quad 15 & 2,8\end{array}$

$\begin{array}{lll}\text { Podrijetlo } & & \\ \text { gradsko } & 170 & 32 \\ \text { seosko } & 363 & 68\end{array}$

Pitali smo učenike/studente o općem aspektu karte kojoj bi, pri četiri vrste scenarija turističkog iskustva, dali prednost. Kako ih je opisao Todd Bacastow (2014), oni su izvedeni iz glavnih funkcionalnih prostornih sposobnosti, pojmova prostornog razmišljanja: kontekst, prepoznavanje prostornih uzoraka, podsjećanje na prethodno promatrane predmete, integracija serija promatranja, rotacija objekta i vizualizacija scene (tablica 2).

Istodobno smo proveli procjenu različitih vrsta upotrebe karte za vrijeme vođenja ture. $U$ tu smo svrhu proveli intervjue sa šest lokalnih vodiča i zaposlenicima turističkog informacijskog centra na tom području (tablica 3).

Scenariji turistickog iskustva napravljeni su kako bi se utvrdile potencijalne preferencije posjetitelja za aktivnim ili pasivnim obilježjima ture unutar zaštićenog područja planina Gutai i gornje doline Mara. Radna hipoteza bila je da će turisti dati prednost obilascima s manje aktivnosti (Moyle i dr. 2014), osim ako se ne stvori 
Table 2 Functional spatial abilities embedded in the survey

\begin{tabular}{|c|c|}
\hline Functional spatial abilities & Survey item \\
\hline Context & $\begin{array}{l}\text { Type of data to support decisions } \\
\text { - overall colour of the map } \\
\text { - outline of protected area } \\
\text { - storyboard }\end{array}$ \\
\hline $\begin{array}{l}\text { Spatial patterns } \\
\text { recognition }\end{array}$ & $\begin{array}{l}\text { Shapes and bodies } \\
\text { - contour lines } \\
\text { - shaded relief } \\
\text { - 3D rendering } \\
\text { - vegetation }\end{array}$ \\
\hline $\begin{array}{l}\text { Previously observed } \\
\text { object recall }\end{array}$ & $\begin{array}{l}\text { Location memory } \\
\text { - landmarks } \\
\text { - stopping-points } \\
\text { - look-out points } \\
\text { - media overlays }\end{array}$ \\
\hline $\begin{array}{l}\text { Integration of } \\
\text { observation series }\end{array}$ & $\begin{array}{l}\text { Forming a coherent (mental) } \\
\text { image of the place } \\
\text { compiling the historic trail } \\
\text { with scientific discourse on } \\
\text { the volcanic relief and nature } \\
\text { reserve }\end{array}$ \\
\hline $\begin{array}{l}\text { Object rotation and } \\
\text { scene visualization }\end{array}$ & $\begin{array}{l}\text { Managing different perspectives } \\
\text { - 2D and 2.5D views from } \\
\text { South and North } \\
\text { - 3D visualization platforms }\end{array}$ \\
\hline
\end{tabular}

Table 3 Conceptual framework of the interview with tour guides

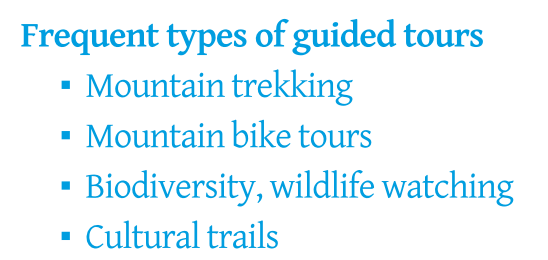

Role of maps during the preparation stage

- Reinforcing details

- Educational - selecting the most suitable maps to share with tourists

On-line preparation sources

- Meteorology and other forecast sites

Role of maps during the tour

- To confirm location and route

Types of maps preferred by guides

- Topographic maps

- Tourist trail maps

- Other thematic maps (mostly geological maps)

Types of maps preferred by tourists

(as observed by guides)

- Simple tourist maps

- Topographic maps

Support for maps - printed, online, GPS

- On-line/GPS during walking stages

- Printed for explanations map in the eco destination (URL3), a cycling tour map (URL4) and a Greenway project (URL5) which has a basic map of the area as output (Figure 1), adapted for different scenarios.

\section{Results and discussion}

3.1 The role of the story told by the map in managing tourist experiences

Stopping-points and milestones, some ordinary, and some with particular significance, were identified through rigorous documentation and tasks related to new tourist products.

An experience-centric management perspective began to be used in the economy starting in 1990 (Pine and Gilmore, 1999). It was defined as the opposite of product management, since travelling was considered to be more about experience and fulfilment. Experience enhances active participation and triggers innovation. Depending on the level of engagement, tourist activities may be considered passive or active (Table 4).

A storytelling map combines a classic map with other digital content to tell a story in a new, creative way. At first glance, the story in this case was a linear narrative presenting the epic adventures of the national hero Pintea the Brave, an outlaw sometimes called the 'Romanian Robin Hood', who lived in Maramures in the late 17th century. His adventures intersected with several geomorphic features related to volcanic activity, which might help explain their fantastic nature. The story combines legend and scientific explanations. To support it, the spatial data on the map were presented in a logical structure: base map, imagery, and tabular for the trails (processed for optimum visualization and according to the pre-testing results).

KiG No. 30, Vol. 17, 2018, https://doi.org/10.32909/kg.17.30.2 - - 
Tablica 2. Funkcionalne prostorne sposobnosti ugrađene u anketu

\begin{tabular}{|c|c|}
\hline $\begin{array}{l}\text { Funkcionalne prostorne } \\
\text { sposobnosti }\end{array}$ & Element ankete \\
\hline Kontekst & $\begin{array}{l}\text { Tip podataka koji podržava odluke } \\
\text { - opća boja karte } \\
\text { - izgled zaštićenog područja } \\
\text { - ploča scenarija }\end{array}$ \\
\hline $\begin{array}{l}\text { Prepoznavanje } \\
\text { prostornih uzoraka }\end{array}$ & $\begin{array}{l}\text { Oblici i tijela } \\
\text { - izohipse } \\
\text { - sjenčani reljef } \\
\text { - 3D prikazi } \\
\text { - vegetacija }\end{array}$ \\
\hline $\begin{array}{l}\text { Sjećanje na prethodno } \\
\text { promatrani objekt }\end{array}$ & $\begin{array}{l}\text { Pamćenje mjesta } \\
\text { - znamenitost } \\
\text { - stajalište } \\
\text { - vidikovac } \\
\text { - sloj na mediju }\end{array}$ \\
\hline $\begin{array}{l}\text { Integracija serija } \\
\text { promatranja }\end{array}$ & $\begin{array}{l}\text { Formiranje koherentne (mentalne) } \\
\text { slike mjesta } \\
\text { - sastavljanje povijesne staze sa } \\
\text { znanstvenim diskursom o } \\
\text { vulkanskom reljefu i } \\
\text { prirodnom rezervatu }\end{array}$ \\
\hline $\begin{array}{l}\text { Rotiranje objekta } i \\
\text { vizualizacija scene }\end{array}$ & $\begin{array}{l}\text { Upravljanje raznim perspektivnim } \\
\text { prikazima } \\
\text { - 2D i 2,5D pogledi s juga i sjevera } \\
\text {-3D platforme vizualizacije }\end{array}$ \\
\hline
\end{tabular}

Tablica 3. Konceptualni okvir intervjua s turističkim vodičima

\author{
Česti tipovi vođenih tura \\ - planinarenje \\ - biciklističke ture po planinama \\ - promatranje biološke raznolikosti i \\ divljih životinja \\ - kulturna staza
Uloga karata tijekom pripremne faze
- pojačavanje detalja
- pedagoška - odabir najprikladnijih karata za dijeljenje s turistima \\ Online izvori za pripremu \\ - meteorologija i druga mjesta za prognozu

\section{Uloga karata za vrijeme ture} \\ - potvrđivanje položaja i staze
}

Tipovi karata kojima vodiči daju prednost

- topografske karte

- turističke karte

- druge tematske karte (uglavnom geološke)

Tipovi karata kojima turisti daju prednost

(uočeno od vodiča)

- jednostavne turističke karte

- topografske karte

Vrste karata prema podršci - tiskane, online, GPS

- online/GPS za vrijeme hodanja

- tiskane za objašnjenja provokativan oglas i uspostavi dobro koordinirana komunikacija. Ako se upotrijebi provokacija bez previše informacija, učinak pripovjedne karte na višeosjetno iskustvo može biti neuvjerljiv. Svaki je scenarij prikazan određenom kartom područja. Međutim, izrada scenarija imala je za polazište klasičnu kartu planinarske karte za eko odredišta (URL3), kartu za obilazak biciklima (URL4) i projekt Greenway (URL5). To je dalo osnovnu kartu područja (slika 1), u konačnici prilagođenu različitim scenarijima.

\section{Rezultati i rasprava}

\subsection{Uloga priče koju priča karta u upravljanju iskustvom turista}

Rigorozna dokumentacija i zadatci vezani za nove turističke proizvode naznačili su stajališta i putokaze, neke značajne, a ostale uobičajene.
Perspektiva upravljanja usredotočena na iskustvo često se koristi u gospodarstvu počevši od 1990. godine (Pine i Gilmore 1999). Takvo je upravljanje definirano kao suprotnost upravljanja proizvodima zbog uvjerenja da se putovanje temelji više na iskustvu i ostvarenju. Ipak, iskustvo povećava aktivno sudjelovanje i potiče inovacije. Ovisno o razini angažmana, turističkim se aktivnostima može pristupiti pasivno ili aktivno (tablica 4).

Pripovjedna karta kombinira klasičnu kartu s drugim digitalnim sadržajem kako bi ispričala priču na novi način. Na prvi pogled, priča je linearna pripovijest koja predstavlja epske avanture nacionalnog junaka Pintea Viteazula, rumunjskog Robina Hooda, koji je živio u Maramureşu krajem 17. stoljeća. Staza prolazi kroz nekoliko geomorfoloških obilježja povezanih s vulkanskom aktivnošću koja bi mogla objasniti fantastičnu priču avanture. Priča se sastoji od dviju vrsta teksta: legende i znanstvenog objašnjenja. Kako bi se podržala priča, 
Table 4 Results of pre-testing: the most relevant elements to be included in the mapping process

\begin{tabular}{|c|c|c|c|}
\hline Level of participation & $\begin{array}{l}\text { Type of tourist } \\
\text { activity }\end{array}$ & Type of story & Map feature \\
\hline Passive absorption & Entertainment & Drama & $\begin{array}{l}\text { Relevant stopping-points } \\
\text { Plot twist multimedia }\end{array}$ \\
\hline Active absorption & Education & Documentary & $\begin{array}{l}\text { Visualization enhancers } \\
\text { Interactivity } \\
\text { On-line integration } \\
\text { Scientific accuracy }\end{array}$ \\
\hline Passive immersion & Aesthetic gazing & Artistic & $\begin{array}{l}\text { Spectacular viewpoints } \\
\text { General aspect }\end{array}$ \\
\hline Active immersion & Escapist & Fantasy & $\begin{array}{l}\text { Path developed with the structure } \\
\text { of a legend: characters, challenges, } \\
\text { happy end } \\
\text { New characters and trails as } \\
\text { bonuses }\end{array}$ \\
\hline
\end{tabular}

Tablica 4. Rezultati aktivnosti predtestiranja: najznačajniji elementi koji će biti uključeni u kartu

\begin{tabular}{|c|c|c|c|}
\hline Razina sudjelovanja & $\begin{array}{l}\text { Tip odgovarajuće } \\
\text { turističke aktivnosti }\end{array}$ & Vrsta priče & Obilježje karte \\
\hline pasivna apsorpcija & zabava & drama & $\begin{array}{l}\text { relevantna stajališta } \\
\text { multimedijski preokret }\end{array}$ \\
\hline aktivna apsorpcija & obrazovanje & dokumentarna & $\begin{array}{l}\text { pojačivači vizualizacije } \\
\text { interaktivnost } \\
\text { online integracija } \\
\text { znanstvena točnost }\end{array}$ \\
\hline pasivno uranjanje & estetski pogled & umjetnička & $\begin{array}{l}\text { spektakularna gledišta } \\
\text { opći aspekt }\end{array}$ \\
\hline aktivno uranjanje & bijeg/sanjarenje & fantazija & $\begin{array}{l}\text { scenarij razvijen prema } \\
\text { strukturi bajke: likovi, izazovi, } \\
\text { sretan završetak } \\
\text { nove osobe i staze kao bonus }\end{array}$ \\
\hline
\end{tabular}




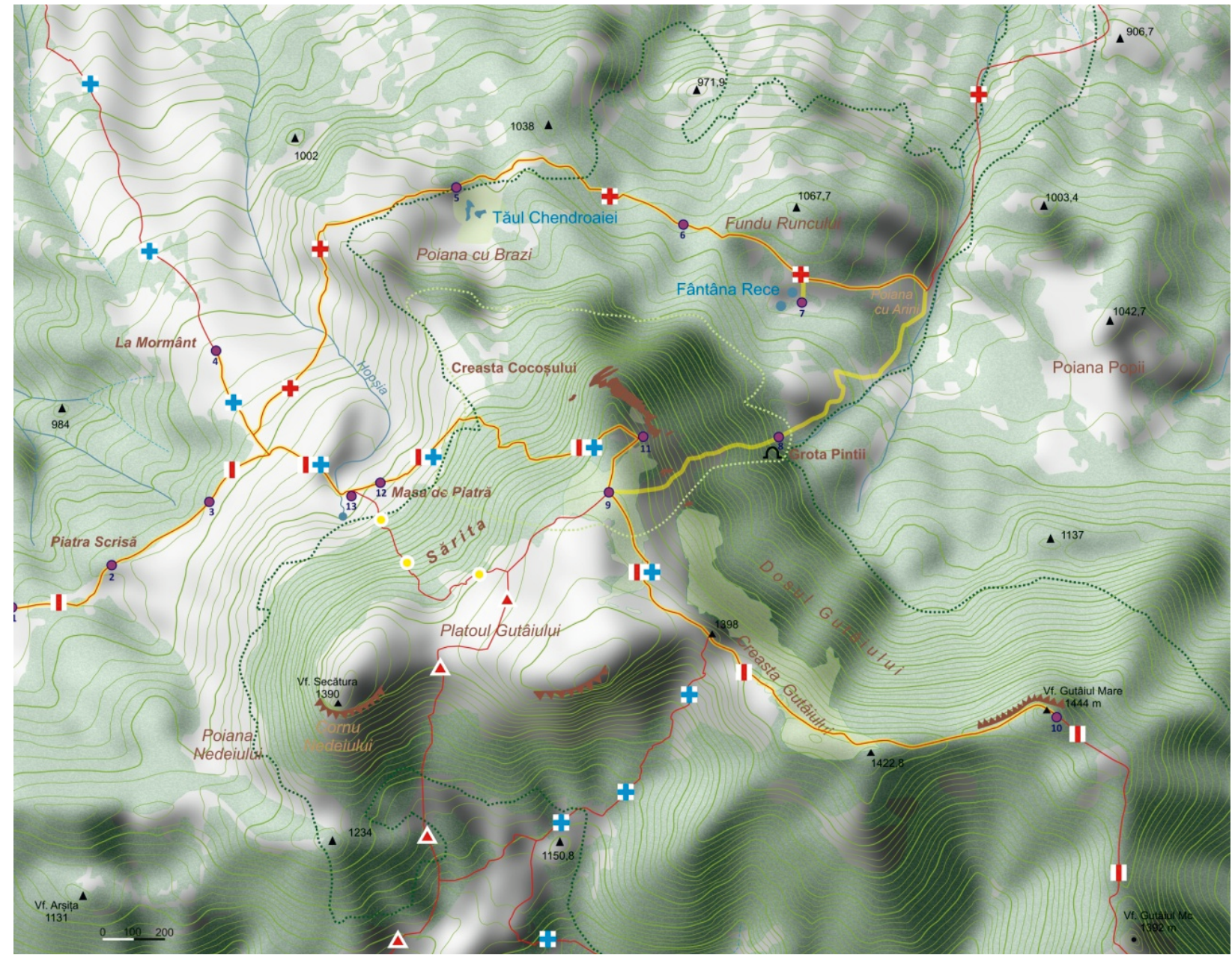

Fig. 1 Upper Mara Valley - base map for the storytelling project (excerpt)

Slika 1. Gornja dolina Mara - osnovna karta za pripovjedni projekt (isječak)

prostorni podatci organizirani su prema logičkoj strukturi - osnovnoj karti, slikama, tablicama, obrađeni za optimalnu vizualizaciju i prema rezultatima prije spomenutog prethodnog testiranja.

Multimedijski sadržaj ugrađen je u web verziju karte. Osim tradicionalnih fotografija i videozapisa, sadrži izvatke iz filma o Pintea Viteazulu proizvedenom 1976., nekoliko verzija balade, audio i tekst, čak i brošure o toj temi. Poboljšivači iskustva još uvijek su u fazi testiranja. Dva se tekuća projekta usredotočuju na proširenu stvarnost s markerima heroja koji su tiskani na karti i 3D terenu u igri Unity.

\subsection{Glavne značajke turističke karte koje bi mogle potaknuti zajedničko stvaranje iskustava}

Turist stvara iskustvo s drugim turistima i pružateljima usluga (Ritchie i Crouch 2003). To je postalo predmetom istraživanja za vodiče (Weiller i Black 2015). Vodiči se često koriste digitalnim medijima kako bi turistima olakšali pristup određenim sadržajima, uključu- jući i karte. Zbog svoje fleksibilnosti i pristupačnosti karta je jednostavan alat za stvaranje iskustava.

\subsubsection{Pasivna apsorpcija}

Ovo je tiskana karta za klasičnu turu koja je utemeljena uglavnom na označenim stazama, pojačana za povijest lika, kojem je ime Pintea Viteazul, relevantnim zaustavljanjima: stol, skok, špilja, grobnica itd. Kako bi se povećao broj posjetitelja, ona ima online sadržaj s video sadržajem i turom na Googleu (slika 2).

\subsubsection{Aktivna apsorpcija}

Karte proizvedene za obrazovanje obično se slažu s pripovjednim kartama. Naša karta ima značajke dokumentarca, koristimo se poboljšanom vizualizacijom i interaktivnošću integriranja online sadržaja kako bi se prikazala određena znanstvena točnost o ugašenim vulkanima na tom području. Priča isprepliće stajališta na prvoj karti (s povijesnim slojem) i objašnjava nekoliko 


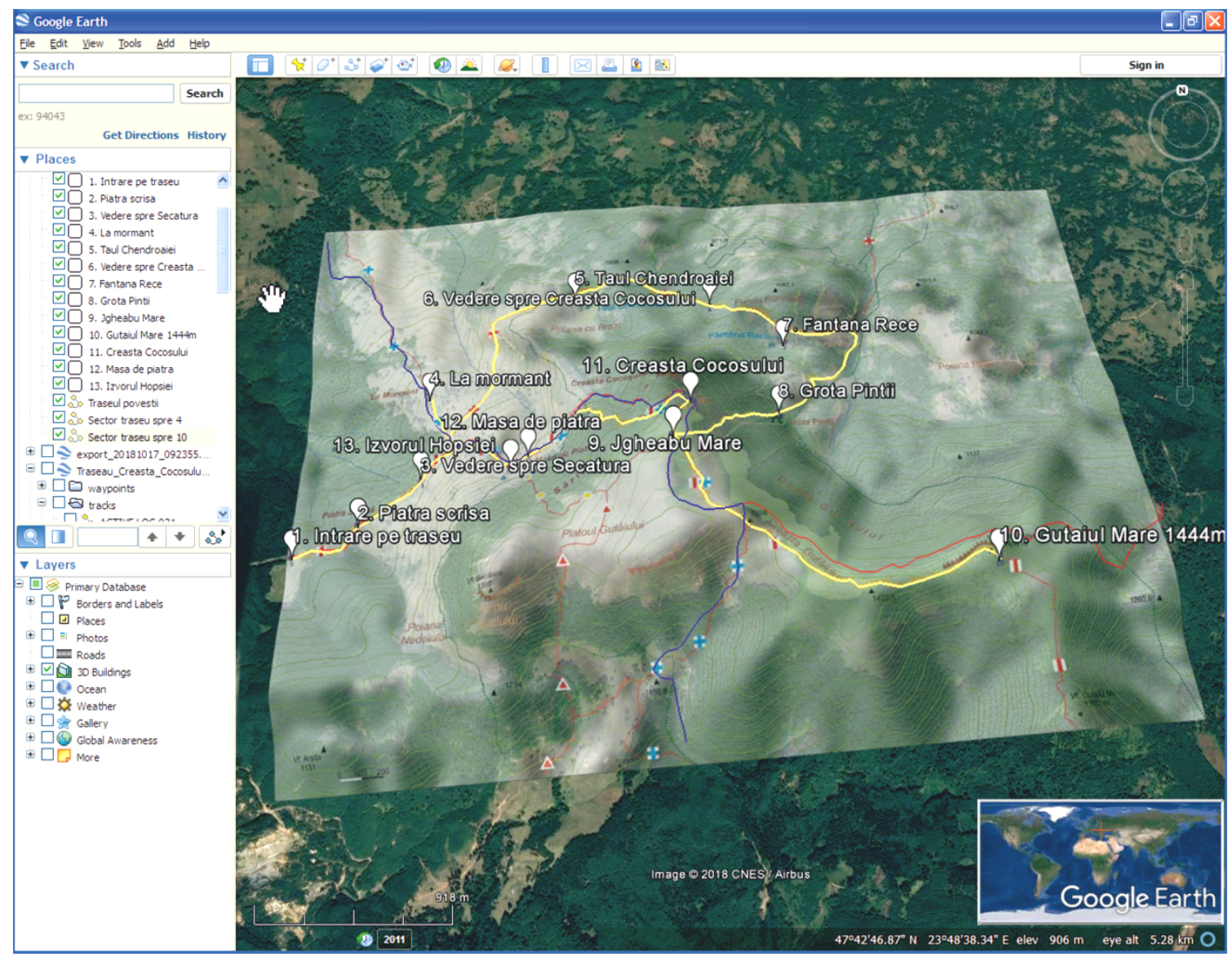

Fig. 2 Upper Mara Valley on-line version and tour

Slika 2. Gornja dolina Mara - online verzija i obilazak

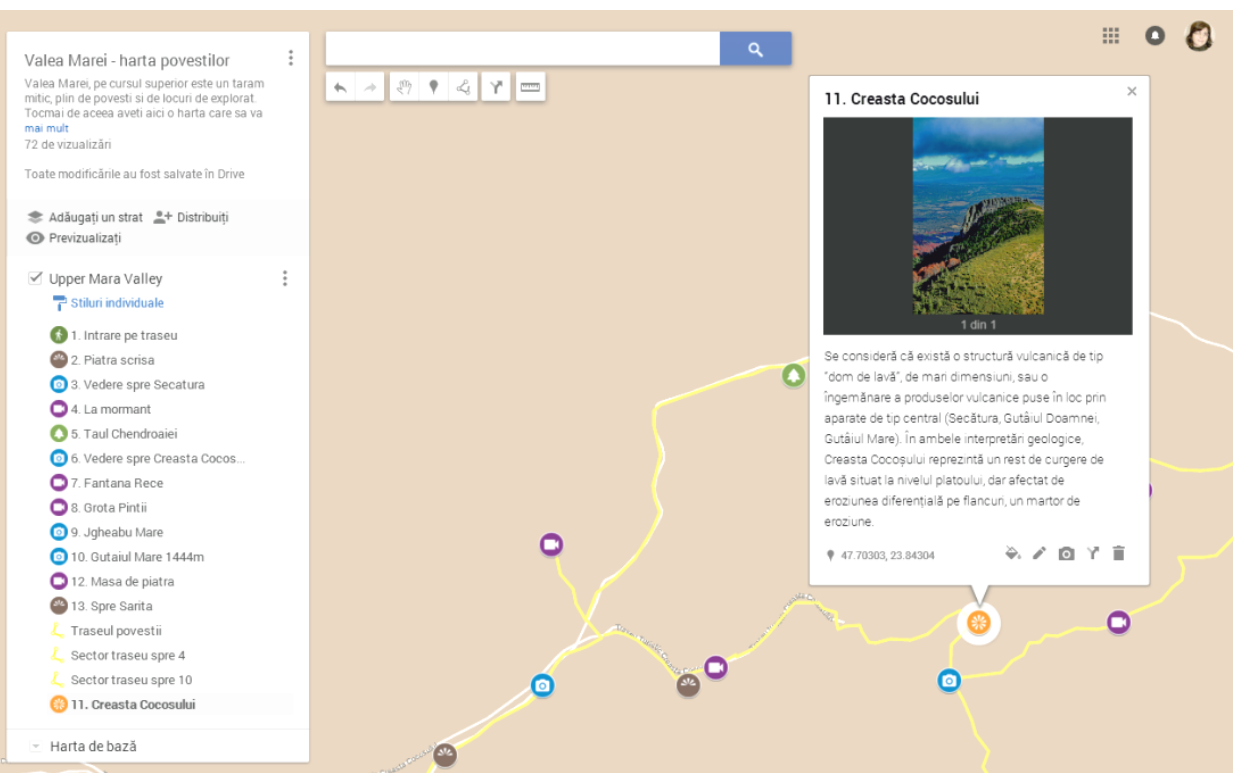

3.2 Main features of a tourist map to trigger experience co-creation

Each tourist co-creates their experience with other tourists and service providers (Ritchie and Crouch 2003). This has become a research subject in relation to tour guides (Weiller and Black 2015). Tour guides often use digital media to facilitate tourist access to specific contents, including maps. Our map is an easy

KiG No. 30, Vol. 17, 2018, https://doi.org/10.32909/kg.17.30.2 - - 


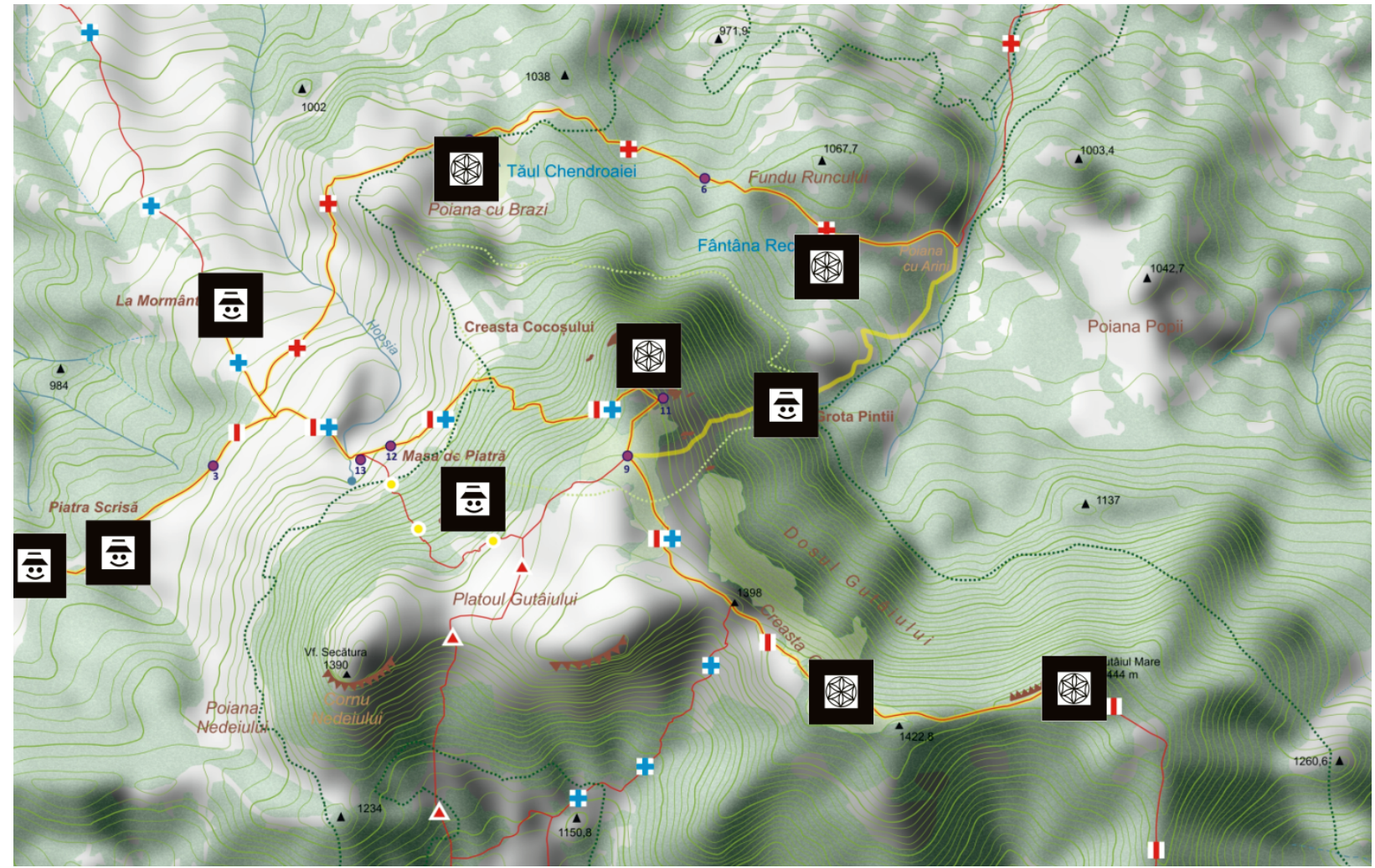

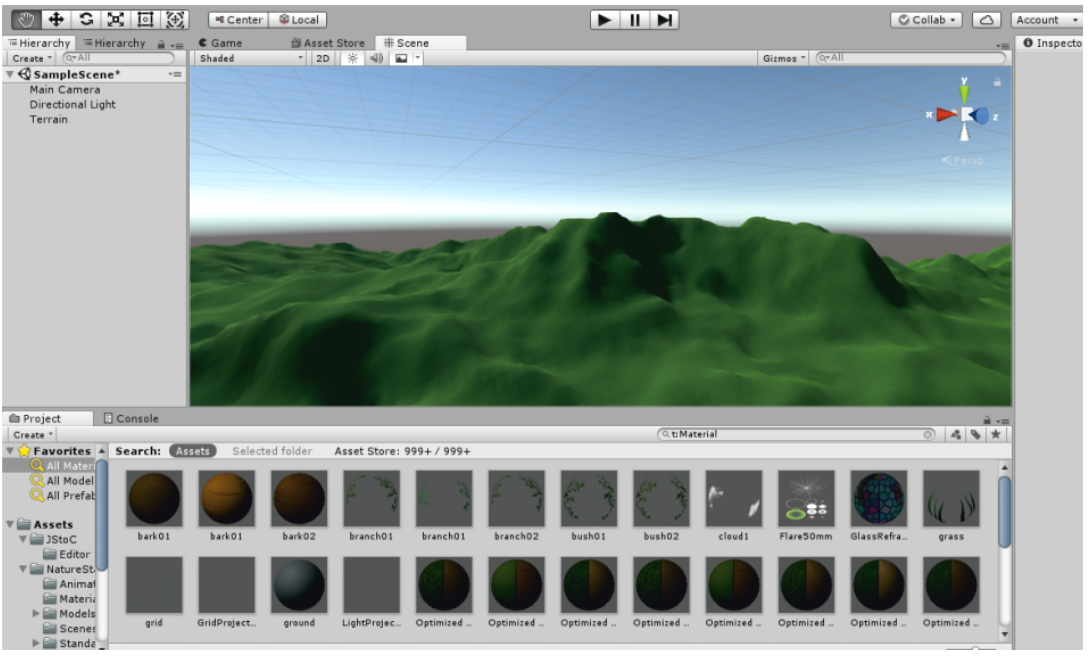

Fig. 3 AR markers printed on the map and sample view of the 3D terrain in Unity

Slika 3. Oznake proširene stvarnosti otisnute na karti i prikaz uzorka 3D terena u igri Unity geomorfoloških aspekata: Pintein stol zapravo je svjedok diferencijalne erozije, Spilja je rasjedna linija pećine koja se formira unutar struktura kratera na koje utječu lokalni tektonici, trag na grebenu pokazuje oblik vulkanskog tijela, Skok je litica s vulkanskom stijenkom, itd. Sve su te priče ispripovijedane uz tiskanu kartu s oznakama proširene stvarnosti (slika 3).

\subsubsection{Pasivno uranjanje}

Opći aspekt karte koji sadrži vidljive točke i uzorke panorama posvećen je estetskom gledanju i pomaknutoj perspektivi, pogledu na jug, sa skicom staze i zanimljivim točkama za pronalaženje slika (foto, video).

\subsubsection{Aktivno uranjanje}

Kako bi se približila sanjarima, mladim turistima željnima fantazije, karta prikazuje stazu sa strukturom bajke: herojskim likovima, izazovima, sretnim završetkom. Međutim, ta karta funkcionira kao osnovna karta za igru koja se oko priče razvija.

\section{Zaključci}

Prikazana karta osmišljena je kako bi se povećala iskustva mladih turista tijekom aktivnosti na otvorenom, a nije usluga vođenja ture ili proizvod turoperatora. Pripovjedne karte temeljene na webu sve su popularnije 
tool for co-creating experiences, due to its flexibility and accessibility.

\subsubsection{Passive absorption}

Our map is printed for a classic tour mostly based on marked trails and enhanced by relevant stoppingpoints relevant to Pintea the Brave and his adventures: the table, the leap, the cave, the tomb, and so on. To attract more visitors, it has an on-line teaser with video content and a Google tour (Figure 2).

\subsubsection{Active absorption}

Educational mapping products are usually like this one, with documentary feature visualization enhancers, and interactive integration of on-line content (in this case, to provide scientific information on extinct volcanoes in the area). The story connects the stoppingpoints on the first map (with a historical overlay) and explains several geomorphological aspects. Pintea's table is actually a record of differential erosion, the cave is a fault line cavern formed within the crater structures affected by local tectonics, the trail on the ridge follows the contour of the volcano, the leap is a cliff with a volcanic rock face, and so on. All the stories are told using a printed map with AR markers (Figure 3).

\subsubsection{Passive immersion}

The general aspect of the map with outlook points and sample panoramas is intended for aesthetic gazing, while a shifted perspective, looking southwards, shows a sketch of the trail and points of interest for image retrieval (photo, video).

\subsubsection{Active immersion}

In order to attract young tourists who are into fantasy and escapism, the map presents the trail through a legend: the heroic characters, their challenges and adventures, and the happy end. It also forms a base map for a game developed around the story.

\section{Conclusions}

The map is designed to enhance young tourists' experience during outdoor activities, rather than selling tour guide services and products. Web-based storytelling maps have become increasingly popular, as they provide access to otherwise inaccessible places or services. A printed map can mediate the storytelling process (with help from the telecommunications infrastructure - mobile coverage and good internet speed).

Tourism studies capitalizing on Pine and Gilmore's experience realms (1999) were drawn on to determine engagement levels and absorption-immersion and passive-active approaches. Investigating functionality issues offered solutions and outlined the necessary features of the map and related content. Measurements of visitor preferences in a range of scenarios were used as the baseline for the map design. In addition, embedded innovative features such as AR or a 3D game terrain were considered to be enhancers with a high potential for future studies. 
među nastavnicima i trgovcima jer nude poticaje na inače nedostižna mjesta ili usluge. Opipljivi objekt - tiskana karta posreduje u procesu pripovijedanja (uz pomoć telekomunikacijske infrastrukture: mobilnog pokrivanja i dobre internetske brzine). Utvrđivanje razine angažmana kombiniranih koncepata proizašlih iz turističkih studija kapitaliziraju iskustva Pinea i Gilmorea (1999): apsorpcijsko uranjanje i pasivno-aktivan pristup. To je bila faza kada je ispitivanje problema funkcionalnosti ponudilo rješenja i ukazivalo na značajke karte i srodnih sadržaja. Mjerenja preferencije posjetitelja u rasponu scenarija smatrali su se osnovom za izradu karte. Međutim, ugrađivanje inovativnih značajki, kao što su proširena stvarnost ili 3D terena za igre, uočene su kao pojačivači s visokim potencijalom za buduća istraživanja.

\section{References / Literatura}

Bacastow T (2014) The Learner's Guide to Geospatial Analysis, The Pennsylvania State University. https://www.e-education.psu.edu/sgam/node/196 Accessed 15 Jan 2018

ESRI (2012) Telling Stories with Maps A White Paper. http://storymaps.esri.com/downloads/Telling\%20Stories\%20with\%20Maps.pdf Accessed 15 Jan 2018

Moyle BD, Scherrer P, Weiler B, Wilson E, Caldicott R, Nielsen N (2017) Assessing preferences of potential visitors for naturebased experiences in protected areas, Tourism Management, Volume 62, Pages 29-41, ISSN 0261-5177, https://doi.org/10.1016/j.tourman.2017.03.010. http://www.sciencedirect.com/science/article/pii/S0261517717300614 Accessed 15 Jan 2018

Pine II BJ, Gilmore JH (1999) The experience economy: work is theatre \& every business a stage: Harvard Business School Press, Boston

Ritchie JRB, Crouch GI (2003) The competitive destination, a sustainable tourism perspective: Cabi Publishing, Cambridge Strain E (2003) Public places, private journeys. Ethnography, entertainment and the tourist gaze, Rutgers University Press, London Weiler B, Black R (2004) Tour guiding research. Insights, Issues and Implications: Channel view

URL 1: World Wide Fund for Nature (2018), http://www.wwf.ro, Accessed 25 Feb 2017

URL 2: Tourist Information Centre Sighetu Marmatiei (2017), www.turismsighet.ro, Accessed 5 Mar 2017

URL 3: Maramureș Tourist Map, http://ecomaramures.com/wp-content/uploads/2017/11/rafharta.pdf, Accessed 5 Mar 2017

URL 4: Maramureș Bicycle Map, http://ecomaramures.com/wp-content/uploads/2017/06/destinatie-eco-pe-bicicleta-ro.pdf, Accessed 5 Mar 2017

URL 5: Greenway project, http://www.maramuresgreenways.ro, Accessed 5 Mar 2017 